\title{
Study on Factors Influencing the Viscosity of Sodium Carboxymethyl Cellulose Used in Capsule-Mucous Sealers
}

\author{
Fakai Wang $\mathbb{D},{ }^{1}$ Zhongguang Sun $\mathbb{D},{ }^{2,3,4}$ Xuelong Li $\mathbb{D},{ }^{2,5}$ Kequan Wang, ${ }^{2,3,4}$ Deyou Chen, ${ }^{5}$ \\ and $\mathrm{Zhen} \mathrm{Li}^{5}$ \\ ${ }^{1}$ College of Mining Engineering, Guizhou Institute of Technology, Guiyang 550000, China \\ ${ }^{2}$ State Key Laboratory of The Gas Disaster Detecting, Preventing and Emergency Controlling, Chongqing 400037, China \\ ${ }^{3}$ State Key Laboratory of Coal Mine Disaster Dynamics and Control, College of Resources and Environmental Science, \\ Chongqing University, Chongqing 400044, China \\ ${ }^{4}$ China Coal Technology and Engineering Group Chongqing Research Institute, Chongqing 400039, China \\ ${ }^{5}$ College of Energy and Mining Engineering, Shandong University of Science and Technology, Qingdao, Shandong 266590, China
}

Correspondence should be addressed to Xuelong Li; lixlcumt@126.com

Received 3 July 2021; Accepted 11 January 2022; Published 29 January 2022

Academic Editor: Paolo Madonia

Copyright (C) 2022 Fakai Wang et al. This is an open access article distributed under the Creative Commons Attribution License, which permits unrestricted use, distribution, and reproduction in any medium, provided the original work is properly cited.

A decrease in the viscosity of a solution of sodium carboxymethyl cellulose (CMC-Na) is a commonly encountered problem in coalbed methane (CBM) pressure measurement with an apron CMC-Na sealer and capsule CMC-Na sealer. Studies have shown that the factors that can reduce the $\mathrm{CMC}-\mathrm{Na}$ solution viscosity include the hydrogen ion concentration index $(\mathrm{pH})$, the environmental temperature, the drilling and sealing time, and the high-pressure CBM gas environment. In this study, a homemade instrument for measuring the viscosity of a CMC-Na solution under high pressure was used to determine the change laws of the viscosity under different conditions, and comparative tests were performed to investigate various factors affecting the viscosity. The best solution for stabilizing the viscosity was determined and effectively applied at a coal mine site, where an overall improvement in the viscosity behaviour was observed.

\section{Introduction}

Coal is generally a porous medium containing pores and cracks. Coalbed methane (CBM) is mainly produced in associated fractured coal seams and rock formations [1-3].

Connell et al. $[4,5]$ stated that passive coal seam gas prevention and control during the production process make it difficult to prevent direct contact between personnel and underground gas at high concentrations. The occurrence of structural abnormalities and incomplete implementation of drainage measures for coal seam gas are very likely to lead to major gas accidents $[6,7]$. Uncovering coal is the most dangerous process in coal operation. Therefore, ensuring the safety of uncovering coal is an important foundation for safe coal mine construction [8-11]. It is necessary to realize intrinsically safe construction for coal and gas outburst mines. Extraction followed by building involves complex systems engineering [12-15].
CBM is a coproduct of coal mining that is an efficient and clean energy source [16-19]. Coal seam gas poses a threat to safe coal mine production and causes hundreds of deaths every year $[20,21]$. The drainage of coal seam gas is the most fundamental measure required to guarantee safe production in coal mines. Extracting coal seam gas for use can not only reduce the risks involved in coal production but also produce clean energy and reduce environmental pollution $[22,23]$ and thus has the three benefits of safety, energy production, and environmental protection. However, the global warming potential of methane is 25 , which is equivalent to an $8.0 \times 10^{10} \mathrm{~m}^{3} \quad \mathrm{CO}_{2}$ emission volume. Methane release has a severe greenhouse effect $[2,24,25]$.

Gas disasters are one of the important factors restricting the development of the coal industry. As the mining depth and output of mines increase, the threat of gas disasters also increases. The problem of gas release has become the biggest factor restricting the safe and efficient production of coal 
mines. Coal seam gas pressure is the driving force for gas gushing and outbursts and is a measure of the coal gas content. The accurate measurement of the coal seam gas pressure has practical importance for the reasonable formulation of gas control measures in mines and predicting the risk of coal and gas outbursts [26-28].

At present, drilling through layers is the most important method used to determine the initial gas pressure in coal seams. The drilling success rate is affected by many factors and is generally found to be only $70 \%$ in field tests [20]. The success rate of drilling in soft and easily collapsed surrounding rocks is even lower, at below 50\% [22]. This low success rate significantly extends the drilling construction cycle [29-31]. There are numerous microholes and cracks in the soft and easily collapsible coalbeds surrounding boreholes. Frequently encountered problems, such as difficulty in drilling holes, excessively large collapsed holes, and failure of the standard sealing process, prevent the formation of a tight seal when using a solid object to plug cracks around a drill hole. Therefore, gas leaks can easily occur, making it difficult to measure the real coal seam gas pressure. These inaccurate measurements lead to incorrect judgements that can easily underestimate the dangers of potential gas accidents. Boreholes in soft and easily collapsible rock often become embedded with plugging instruments, which considerably increases the cost of coal seam gas pressure measurement. To solve this technical problem, an M-II gas pressure tester (capsule-mucus sealer) is used in conjunction with stepgrouting solid-hole-sealing pressure measurement technology in this study. The basic principle is "solid seals liquid, liquid seals gas" [25]. That is, two expansion capsules are used to construct a drilled confined space. Mucus is pressed into the sealed space of a capsule at a pressure slightly higher than the coal seam gas pressure indicated on the gas meter. Then, the mucus penetrates into the cracks around the borehole to isolate the gas leakage channel under pressure, such that the real gas pressure of the coal seam is measured [30, 32, 33]. A schematic of the capsule-mucus sealer is shown in Figure 1.

The M-II gas pressure tester is used in combination with step-grouting and hole-fixing pressure measurement technology to consolidate soft and easily collapsible surrounding rock. The microholes and cracks in the surrounding rock of the borehole are sealed. The M-II gas pressure manometer is supported and protected to successfully complete the pressure measurement. This system can effectively prevent the collapse of the surrounding rock of the borehole and the loss of a pressure gauge. This system can be used to accurately measure the initial coal seam gas pressure and successfully recover a gas pressure tester.

A plugging device exploits the permeation effect of a highpressure carboxymethyl cellulose- $\mathrm{Na}(\mathrm{CMC}-\mathrm{Na})$ solution to infiltrate a limited spatial range around a borehole to block gas. The device is inserted over a prescribed spatial range of rock or coal cracks, and possible passage from the gas chamber to the outside is blocked, thus ensuring that the gas in the chamber does not leak. Replacing gas with nonviscous water $[34,35]$ may result in leakage along the fractured zone of the rock surrounding the borehole, making it difficult to create and maintain sufficient osmotic pressure [36-38].
However, field application has shown that the CMC$\mathrm{Na}$ solution viscosity after sealing decreased to varying degrees [2]. The factors that have been identified to decrease the viscosity are microbial bacterial decomposition, solution hydrogen ion concentration index $(\mathrm{pH})$, coal seam gas pressure, and decomposition from CMC-Na instability [35]. The ambient temperature also significantly affects the CMC-Na solution viscosity. Changes in the temperature cause thermal expansion and contraction, thereby changing the volume and density of the CMC-Na solution [28]. In addition, temperature changes cause changes in the resistance of the plugging device [29]. Therefore, temperature was considered to be an influencing factor for the CMC-Na solution viscosity in the experiments performed in this study. Experiments were performed to identify the factors that may affect the viscosity, and a method for stabilizing the CMC-Na solution viscosity was proposed. The objective of this study was to develop a method for accurately measuring the initial coal seam gas pressure at a coal mine site. This study serves as a useful reference for the formulation of gas prevention and control plans and a reliable guide for safe coal mine production.

\section{Experimental Research}

2.1. Experimental Equipment. CMC-Na is generally used as the material for pluggers in coal mines [39-42]. To accurately measure the CMC-Na solution viscosity under high-pressure gas conditions [43-45], an NDJ-5 series rotary digital viscometer produced by China Shanghai Fangrui Instrument Co., Ltd., was used in this study.

Most of the experiments performed in this study involve measuring the viscosity of CMC-Na solutions under atmospheric pressure. To meet the experimental requirements, a cylindrical high-pressure vessel was designed in-house and is shown in Figure 2.

The instruments and materials required for this experimental work included an NDJ-5 series digital display viscometer, a cylindrical high-pressure container, an electronic balance, a gas cylinder, a timer, a glass cup, a pipette, a graduated cylinder, a glass rod, a dropper, an ear ball, and a constant-temperature bath.

2.2. Experimental Procedure. The experimental procedure is described below.

An ODEON portable water-quality probe made by the French company Ponsel was used for the on-site measurement of basic water-quality indicators, such as the water temperature (T), pH, dissolved oxygen (DO) and TDS, and an alkalinity kit produced by the German company Merck was used to titrate the alkalinity on-site, where the titration accuracy was $0.1 \mathrm{mmol} \cdot \mathrm{L}^{-1}$. The cations were detected using a Di'an ICS1500 ion chromatograph, and the anions were detected using a Metrohm MIC ion chromatograph. The difference between the anion and cation charge balance was $<5 \%$. Statistical results for the conventional chemical parameters of groundwater are shown in Table 1. 


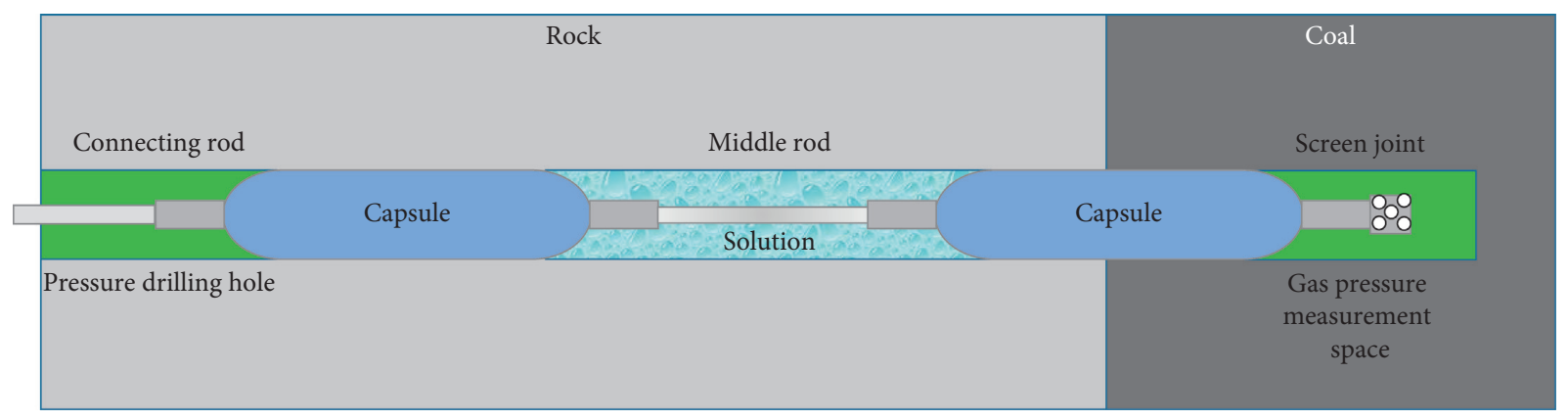

Figure 1: Capsule-mucus sealer schematic.

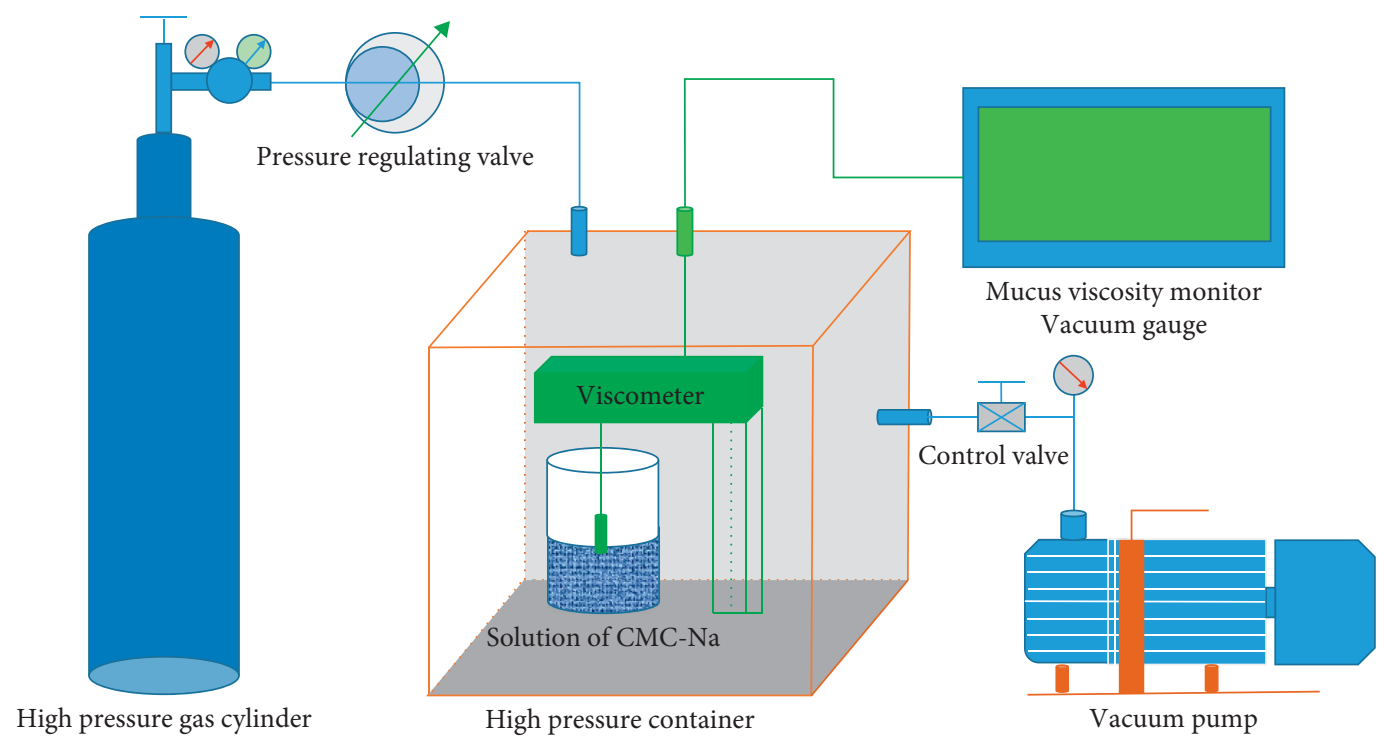

FIgURE 2: Schematic diagram of the experimental setup.

TABLE 1: Statistical results for conventional chemical parameters of groundwater $\left(\mathrm{mg} \cdot \mathrm{L}^{-1}\right)$.

\begin{tabular}{lccccccccccccc}
\hline Sample & $\mathrm{pH}$ & $\mathrm{C}\left({ }^{\circ} \mathrm{C}\right)$ & $\mathrm{K}^{+}$ & $\mathrm{Na}^{+}$ & $\mathrm{Ca}^{2+}$ & $\mathrm{Mg}^{2+}$ & $\mathrm{HCO}_{3}{ }^{-}$ & $\mathrm{Cl}^{-}$ & $\mathrm{SO}_{4}{ }^{2-}$ & $\mathrm{NO}_{3}{ }^{-}$ & $\mathrm{Si}$ & $\mathrm{DO}$ & $\mathrm{TDS}$ \\
\hline$\# 1$ & 6.66 & 9.35 & 0.44 & 1.30 & 3.53 & 1.25 & 26.16 & 0.41 & 1.15 & 0.84 & 8.60 & 9.03 & 10.60 \\
$\# 2$ & 6.59 & 11.54 & 0.40 & 1.38 & 4.14 & 0.77 & 18.11 & 0.57 & 1.34 & 2.86 & 8.40 & 5.38 & 8.11 \\
\hline
\end{tabular}

Notes: $T=273+\mathrm{C}, \mathrm{K}$.

A groundwater sample and a distilled water sample were used to prepare appropriate volumes of CMC-Na solutions with viscosities at room temperature $\left(20^{\circ} \mathrm{C}\right)$ of $2550 \mathrm{MPa} \cdot \mathrm{s}$ and $2400 \mathrm{MPa} \cdot \mathrm{s}$, respectively. The solutions were divided into several parts and placed in evacuated cylindrical high-pressure containers under standard atmospheric pressure environments containing different gases (air, $\mathrm{CO}_{2}, \mathrm{CH}_{4}$, and $\mathrm{N}_{2}$ ). Over a period of several days, the changes in the viscosity of the solutions in the different environments with time were measured, and the recorded data are presented in Tables 2 and 3.

The results presented in Tables 2 and 3 show that in various gas environments (under vacuum or atmospheric conditions), the viscosity decreases with increasing time over different ranges. The highest and lowest decreases in the viscosity occur in the $\mathrm{CO}_{2}$ and vacuum environments.

The viscosity exhibits the same change trend with time for solutions prepared using the two different water samples in different gas environments but decreases to varying extents. The viscosity of the CMC-Na solution prepared with distilled water is higher than that of the solution prepared with downhole water. The initial viscosity of the two CMC$\mathrm{Na}$ solutions prepared using downhole water is higher than that of the CMC-Na solution prepared with distilled water. This result shows that the decreases viscosity of the solution prepared with groundwater more with time than that of the solution prepared with distilled water. Due to that, groundwater has a greater impact on viscosity stability of the solution prepared than that of distilled water.

\section{Experimental Results and Analysis}

3.1. Effect of the Swelling Time on the Viscosity. CMC-Na is a linear water-soluble polymer. A well-defined swelling time is required for the molecular chain to completely expand in 
TABLe 2: Temporal changes in the viscosity of a CMC-Na solution made with groundwater.

\begin{tabular}{|c|c|c|c|c|c|c|c|}
\hline Project & Environment & $12(\mathrm{~h})$ & $24(\mathrm{~h})$ & $48(\mathrm{~h})$ & $72(\mathrm{~h})$ & $96(\mathrm{~h})$ & $120(\mathrm{~h})$ \\
\hline \multirow{5}{*}{ CMC-Na solution viscosity (MPa.s) } & Vacuum & 2444 & 2346 & 2267 & 2205 & 2188 & 2042 \\
\hline & Air & 2298 & 2201 & 2099 & 1963 & 1808 & 1722 \\
\hline & $\mathrm{CO}_{2}$ & 2203 & 2118 & 2023 & 1824 & 1624 & 1532 \\
\hline & $\mathrm{CH}_{4}$ & 2407 & 2322 & 2215 & 2158 & 2078 & 1986 \\
\hline & $\mathrm{N}_{2}$ & 2438 & 2415 & 2236 & 2189 & 2107 & 1994 \\
\hline
\end{tabular}

TABle 3: Temporal changes in the viscosity of a CMC-Na solution made with distilled water.

\begin{tabular}{lccccccc}
\hline Project & Environment & $12(\mathrm{~h})$ & $24(\mathrm{~h})$ & $48(\mathrm{~h})$ & $72(\mathrm{~h})$ & $96(\mathrm{~h})$ & $120(\mathrm{~h})$ \\
\hline & Vacuum & 2388 & 2364 & 2283 & 2254 & 2209 & 2188 \\
& $\mathrm{Air}$ & 2355 & 2308 & 2234 & 2186 & 2124 & 2018 \\
CMC-Na solution viscosity (MPa·s) & $\mathrm{CO}_{2}$ & 2335 & 2273 & 2188 & 2035 & 1986 & 1901 \\
& $\mathrm{CH}_{4}$ & 2362 & 2312 & 2260 & 2201 & 2143 & 2082 \\
& $\mathrm{~N}_{2}$ & 2351 & 2307 & 2261 & 2223 & 2177 & 2099 \\
\hline
\end{tabular}

solution, whereupon the solution reaches an ideal viscosity. CMC-Na continuously dissociates into polyanions in water, and the hydration group in the molecule is fully hydrated, and $-\mathrm{COO}^{-}$repels each other so that the molecular chain is stretched to accelerate the dissolution of CMC-Na [25]. In addition, in the process of dispersion and swelling, CMC-Na can not only decompose itself to form intramolecular hydrogen bonds, but also combine with water molecules to form hydrogen bonds [2]. Two reasons make the viscosity of the hydrosol liquid increase, and its suitable swelling time should be the time to reach the dissociation equilibrium. Experiments were designed to investigate the relationship between the solution viscosity and the swelling time, and the experimental data points and its fitting curve are shown in Figure 3.

Figure 3 shows that the fitting curve of the CMC-Na solution viscosity with swelling time satisfies the quadratic polynomial formula, which is $y=0.0057 x^{2}+2.1803 x+1873.6$, Correlation coefficient $R^{2}=0.9804$. It shows that the fitted quadratic polynomial formula can explain the trend of CMCNa solution viscosity with swelling time well. When the fitted quadratic polynomial formula shows more than 191 minutes, the viscosity of the hydrosol solution increases with the swelling time. Beyond a swelling time of 191 minutes, the viscosity does not change significantly and is basically stable. The optimal swelling time of CMC-Na is taken to be $191 \mathrm{~min}$.

CMC-Na becomes unstable and self-decomposes. After CMC-Na dissolves in solution over the optimal swelling time, CMC-Na self-decomposes due to instability, and the solution viscosity decreases accordingly.

3.2. Effect of the Temperature on the Viscosity. The CMC-Na solution viscosity depends strongly on the temperature. Under normal temperatures and pressures, a $1 \mathrm{~K}$ change in the temperature results in the liquid viscosity changing by a few percent or even ten percent. The viscosity does not change linearly with the temperature. The change in the solution viscosity depends on the temperature range. The lower the temperature is, the more strongly the solution viscosity depends on temperature. The viscosity of a CMC-

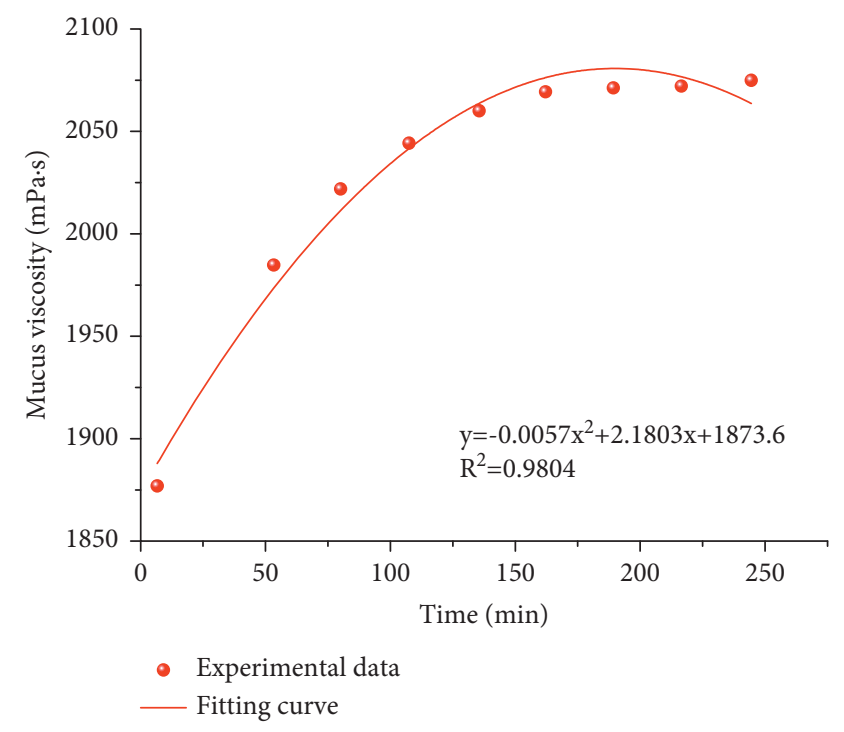

FIgURE 3: Variation curve of CMC-Na solution viscosity with swelling time.

$\mathrm{Na}$ solution is inevitably affected by temperature. Experiments were designed to observe the changes in the solution viscosity with temperature, and the experimental data points and its fitting curve are shown in Figure 4.

Figure 4 shows that the fitting curve of the CMC-Na solution viscosity with temperature satisfies the quadratic polynomial formula, which is $y=0.155 x^{2}+83.153 x+8996.7$, Correlation coefficient $R^{2}=0.9969$. It shows that the fitted quadratic polynomial formula can explain the trend of CMC-Na solution viscosity with temperature well. Figure 4 shows that over a temperature range of $283 \mathrm{~K}$ to $353 \mathrm{~K}$, the solution viscosity decreases as the temperature of the CMC-Na solution increases.

Temperature has a significant effect on the solution viscosity. A test was performed in which the temperature of the CMC-Na solution was raised to $353 \mathrm{~K}$ and then cooled to a low temperature, and the solution viscosity was measured at a low temperature. The viscosity was basically the same as that measured at the initial temperature. 


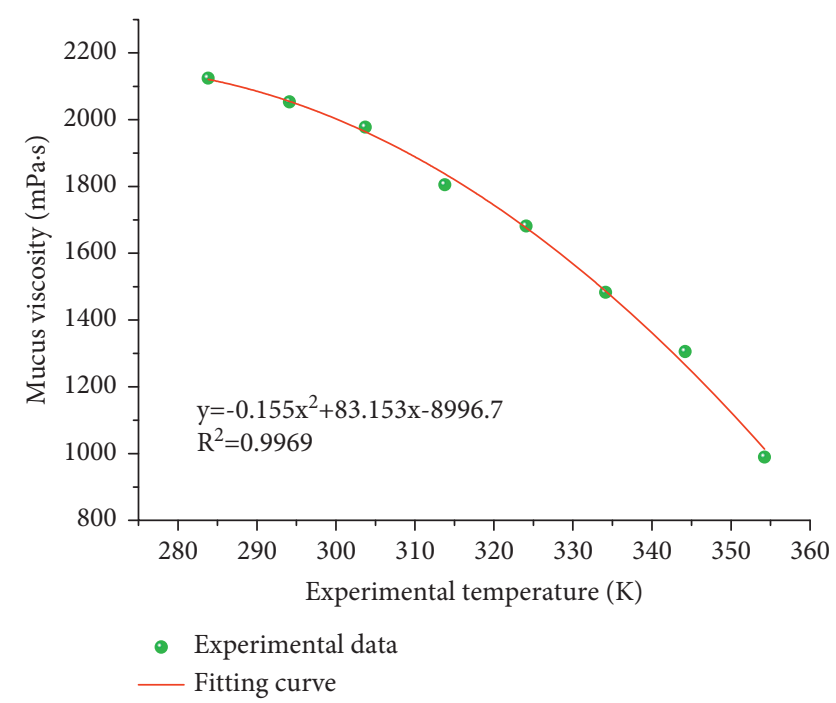

Figure 4: Variation in the CMC-Na solution viscosity with temperature.

3.3. Effect of the Solution $p H$ on the Viscosity. An appropriate volume of a CMC-Na solution was prepared, and different $\mathrm{pH}$ values were calibrated using a standard hydrochloric acid solution with a concentration of $0.1972 \mathrm{~mol} / \mathrm{L}$. At $298 \mathrm{~K}$ and $0.1 \mathrm{MPa}, \mathrm{pH}$ test paper was used to measure the CMC-Na solution $\mathrm{pH}$, the viscosity at different solution $\mathrm{pH}$ values was recorded, and the experimental data points and its fitting curve are shown in Figure 5.

Figure 5 shows that the fitting curve of the CMC-Na solution viscosity with $\mathrm{pH}$ satisfies the quadratic polynomial formula, which is $y=124.57 x^{2}+1956.2 x+4978.4$, Correlation coefficient $R^{2}=0.9649$. It shows that the fitted quadratic polynomial formula can explain the trend of CMC-Na solution viscosity with $\mathrm{pH}$ well. According to Figure 5, it can get that the maximum viscosity of the CMC-Na solution is obtained at a solution $\mathrm{pH}$ of 7-8. Excessively large or small $\mathrm{pH}$ conditions affect the solution viscosity. The solution viscosity can be increased by changing the CMC-Na solution $\mathrm{pH}$.

3.4. Effect of the Pressure on the Viscosity. Based on experience, a constant pressure of approximately $2 \mathrm{MPa}$ is required using the capsule $\mathrm{CMC}-\mathrm{Na}$ sealing device. The environment of an apron pressure sealer is basically sealed in the presence of gas at pressures higher than $2 \mathrm{MPa}$. Generally, the maximum pressure does not exceed $8 \mathrm{MPa}$. An experiment showed that different gas pressure environments can affect the CMC-Na solution viscosity [20].

Equipment was designed to measure the viscosity under high pressure and used in experiments to investigate the effect of pressure on the viscosity; the experimental data are plotted in Figures 6 and 7, and the fitting formula is shown in Tables 4 and 5 .

Figures 6 and 7 show the results of experiments performed at different pressures, where each pressure was allowed to stabilize for a prescribed period of time: the viscosity decreased slightly with increasing ambient gas

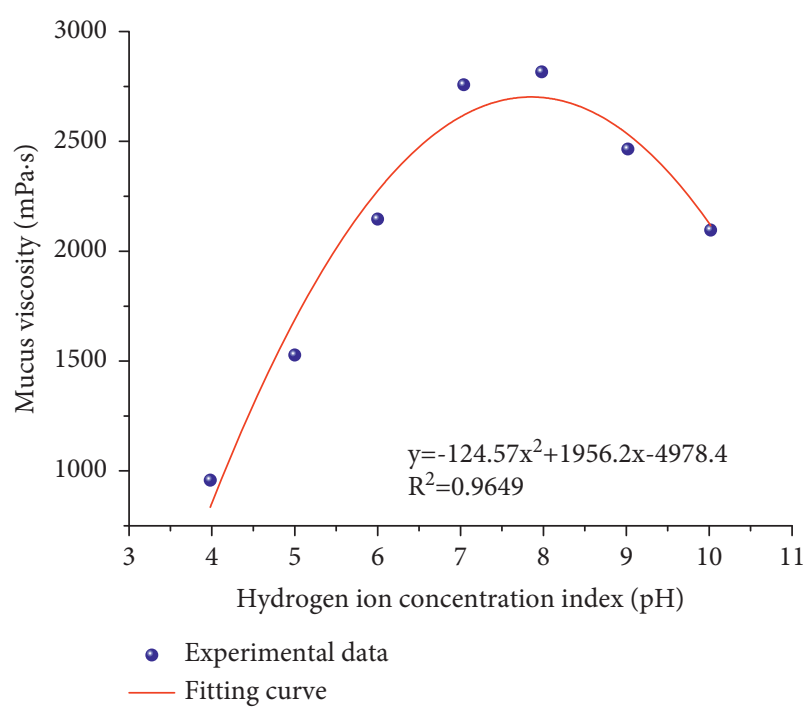

FIgURE 5: Change curve of the CMC-Na solution viscosity with $\mathrm{pH}$.

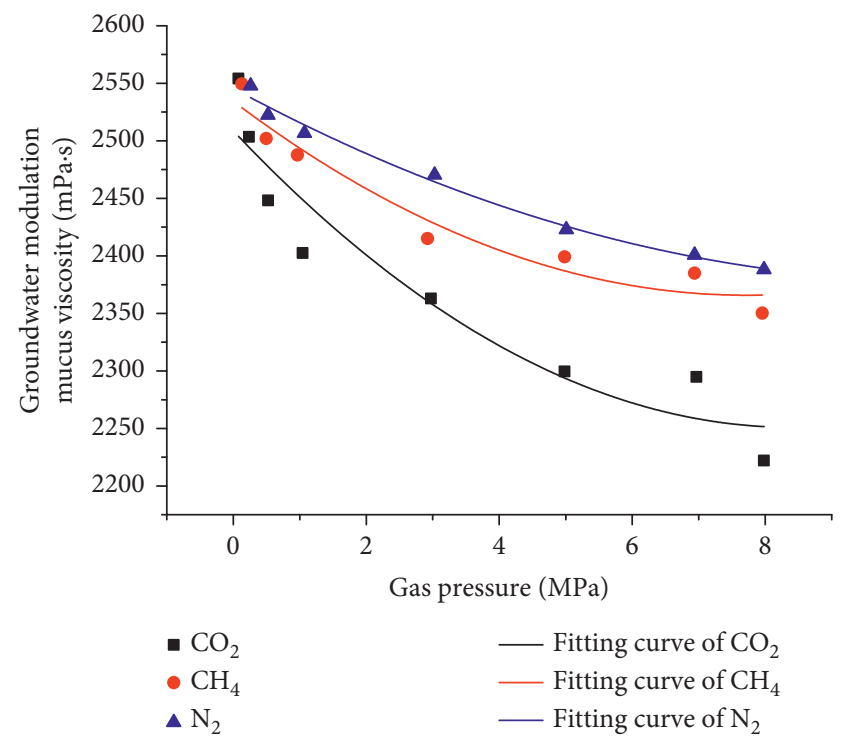

Figure 6: Curve of the viscosity of CMC-Na prepared using groundwater at different pressures.

pressure. The viscosity of the solution prepared with downhole water decreases more than that of the solution prepared with distilled water. The largest reduction in viscosity is observed for $\mathrm{CO}_{2}$; however, the effect of pressure on viscosity reduction is not as large as that of $\mathrm{pH}$ or temperature. The experimental data curves of Figures 6 and 7 show that pressure has a certain effect on viscosity, and the viscosity decreases with increasing pressure. The fitting formulas in Tables 4 and 5 are obtained by fitting the experimental data. The pressure and viscosity are in a quadratic polynomial relationship, and the correlation coefficient value is large, indicating that the data fitting characteristics are good, which has certain guiding significance. Groundwater has a greater impact on CMC-Na polymer than distilled water. As the air pressure increases, groundwater accelerates the decomposition of $\mathrm{CMC}-\mathrm{Na}$ polymer, 


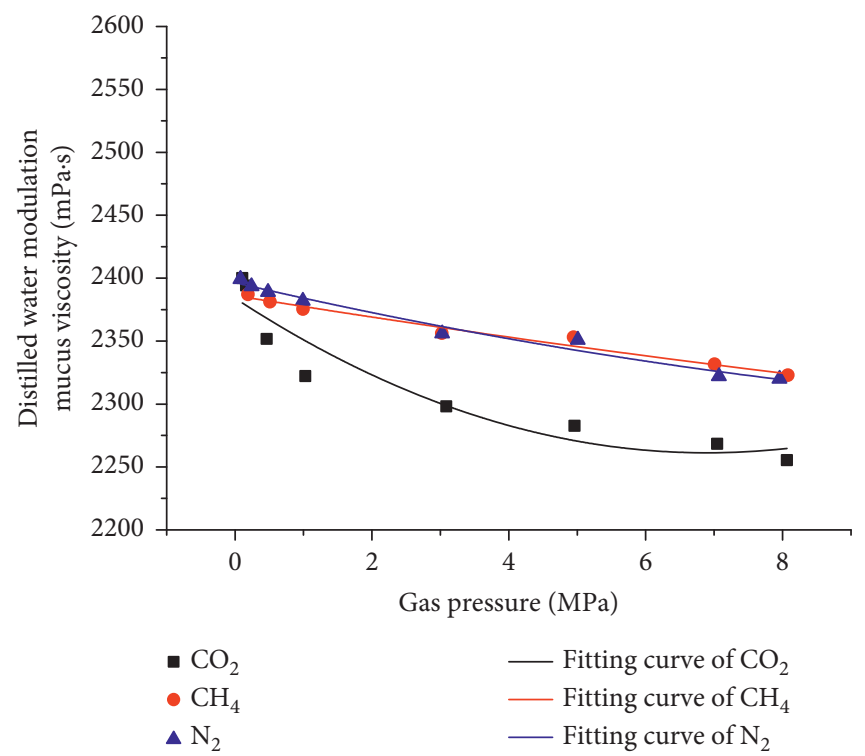

Figure 7: Curve of the viscosity of CMC-Na prepared using distilled water at different pressures.

TABLE 4: Fitting formula of the viscosity of CMC-Na prepared using groundwater at different pressures.

\begin{tabular}{lccc}
\hline Project & Environment & Fitting formula & Correlation coefficient \\
\hline & $\mathrm{CO}_{2}$ & $y=3.6345 x^{2}-61.251 x+2508.7$ & 0.9121 \\
CMC-Na solution viscosity (MPa.s) & $\mathrm{CH}_{4}$ & $y=2.8276 x^{2}-43.669 x+2534.4$ & 0.9503 \\
& $\mathrm{~N}_{2}$ & $y=1.4526 x^{2}-31.197 x+2545.5$ & 0.9893 \\
\hline
\end{tabular}

TABLE 5: Fitting formula of the viscosity of CMC-Na prepared using distilled water at different pressures.

\begin{tabular}{lccr}
\hline Project & Environment & Fitting formula & Correlation coefficient \\
\hline & $\mathrm{CO}_{2}$ & $y=2.5811 x^{2}-35.611 x+2384.1$ & 0.9089 \\
CMC-Na solution viscosity (MPa.s) & $\mathrm{CH}_{4}$ & $y=0.0639 x^{2}-8.1076 x+2385.6$ & 0.9775 \\
& $\mathrm{~N}_{2}$ & $y=0.3719 x^{2}-12.618 x+2396.4$ & 0.9802 \\
\hline
\end{tabular}

resulting in a decrease in the viscosity of CMC-Na solution. In addition, CMC-Na itself is not completely stable [16]. CMC-Na decomposes itself over time, and the viscosity of CMC-Na solution decreases [21].

\section{Field Application}

Figure 8 shows the geographical location of the Lvtang Coal Mine in Bijie city, Guizhou Province, China. The No. 6 coal seam was pressure-tested. Corresponding gas pressure test points are arranged in the C605 working face. The contour line of the coal seam floor is $+1800 \mathrm{~m}$. It is ensured that the coal seam thickness of the 4 test borehole positions at the pressure measuring point is consistent, the occurrence conditions are uniform, the structure is simple, and they are the same geological unit.

The capsule CMC-Na sealer method was used to create a pressure seal, and the aforementioned test method was used to develop a processing method for the CMC-Na solution. The scheme is described below.

(1) Four holes were drilled in the C605 coal seam floor parallel to the seam strike position.
(2) Borehole \# 1 was sealed using a conventional capsule CMC-Na sealing device for pressure measurement.

(3) For Borehole \#2, CMC-Na was treated with $2.5 \%$ formaldehyde and used to create a seal for pressure measurement.

(4) For Borehole \#3, the $\mathrm{pH}$ of the CMC-Na solution was adjusted by the addition of sodium hydroxide and sodium carbonate, and the active pressure measurement method was used to create a pressure seal.

(5) Borehole \#4 was sealed using conventional capsule CMC-Na sealing, and the active pressure measurement method was used to create a pressure seal.

The measured pressures of each borehole were recorded, and the gas pressure curves are shown in Figure 9.

The following conclusions can be drawn from Figure 9.

(1) A comparison of the data obtained for Boreholes \#1 and \#2 shows that the pressures measured over the first 2 days for Borehole \#2 are closer to the maximum pressure than those of Borehole \#1 under the same conditions, indicating that the Borehole \#2 seal is better than the Borehole \#1 seal. The CMC- 


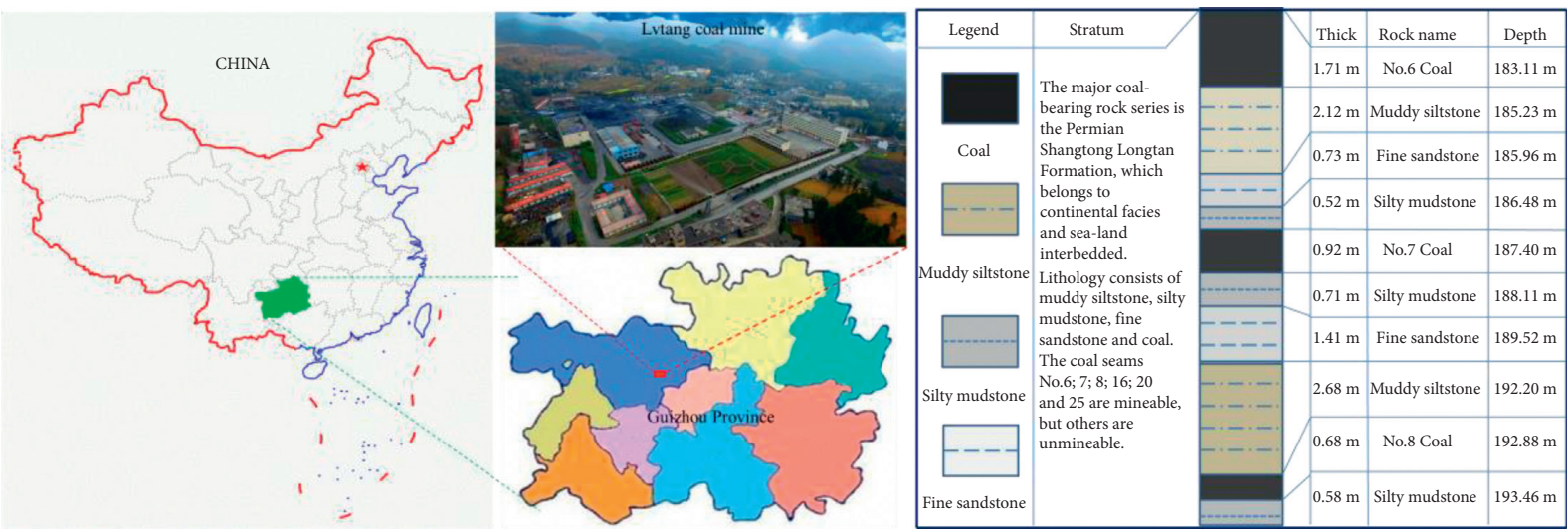

Figure 8: Geographical location of the Lvtang coal mine and the coal seam stratigraphic column.

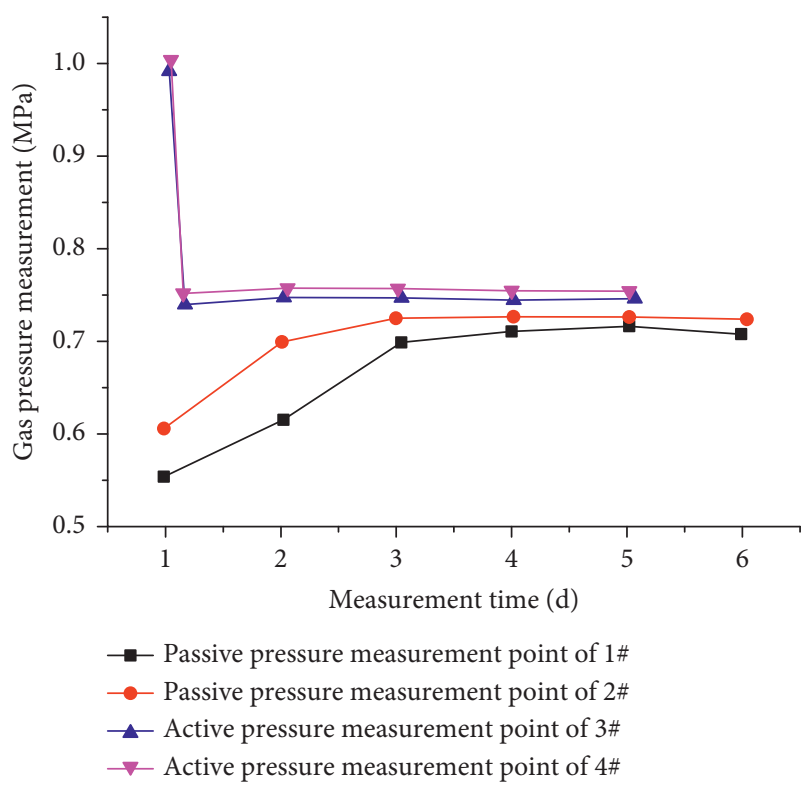

Figure 9: Recovery curve for CBM pressure.

Na solution was recovered after the pressures of the two boreholes were measured and sent to the laboratory for viscosity measurement; the viscosity of the CMC-Na solution recovered from Borehole \#2 is much higher than that recovered from Borehole \#1.

(2) Adopting the active pressure measurement method for Boreholes \#3 and \#4 considerably shortens the measurement time. Over the entire pressure measurement process, the pressures are more stable, and the recovered CMC-Na viscosity is larger for Boreholes \#3 and \#4 than for Boreholes $\# 1$ and \#2.

Finally, the largest pressure is measured for Borehole \#4 and is closest to the initial gas pressure of the coal seam, which is consistent with the conclusion drawn from the laboratory test results. The treated CMC-Na also has superior pressure stability compared to that of the untreated CMC-Na. The reason for this result is that the viscosity is stabilized while reducing the loss of
CMC-Na, which significantly enhances the pressure seal and makes the CMC-Na solution pressure more stable and reliable.

\section{Conclusion}

A self-designed test device was used in this study; comparative tests and analysis were performed using the capsule-mucus sealing device to determine the factors influencing and laws of the CMC-Na solution viscosity in an underground coal seam environment. A scheme to maintain the stability of mucus performance was proposed and verified by field tests. The following conclusions were drawn.

(1) The high-pressure gas environment of the coal seam, the solution $\mathrm{pH}$, the temperature of the coal seam, the sealing time, and other influencing factors deteriorate the CMC-Na solution viscosity.

(2) Beyond the optimal swelling time, CMC-Na becomes unstable and self-decomposes, and the CMC$\mathrm{Na}$ solution viscosity decreases accordingly.

(3) Over a temperature range of $283 \mathrm{~K}$ to $353 \mathrm{~K}$, the CMC-Na solution viscosity decreases as the temperature of CMC-Na increases.

(4) The solution $\mathrm{pH}$ affects the solution viscosity. In the $\mathrm{pH}$ range of $7-8$, the solution viscosity reaches a maximum. For $\mathrm{pH}$ values less than 7 , the solution viscosity is significantly lower than that over the 7-8 $\mathrm{pH}$ range.

(5) The CBM pressure has little effect on the viscosity and can be neglected.

(6) An on-site pressure measurement comparison test verified the feasibility of using a stabilized CMC-Na solution. The viscosity stability of CMC-Na improved steadily, and the accuracy and reliability of the pressure measurement were significantly improved.

\section{Data Availability}

The data used to support the findings of this study are available from the corresponding author upon request. 


\section{Conflicts of Interest}

The authors declare no conflicts of interest.

\section{Authors' Contributions}

Fakai Wang proposed the research. Zhongguang Sun and Xuelong Li prepared figures and tables, Kequan Wang interpreted the structural data. Deyou Chen and Zhen Li developed the main ideas. All co-authors actively contributed to the manuscript with comments, ideas, and suggestions.

\section{Acknowledgments}

This work was financially supported by the Science Innovation and Entrepreneurship Special Funded Projects of China Coal Technology\& Engineering Group (Grant No. 2020-TD-ZD007), the Natural Science Foundation of Chongqing China (Grant Nos. cstc2020jcyj-msxmX0972 and cstc2019jcyj-msxmX0633), the Cultivation and exploration and innovation project of new academic seedlings of Guizhou Institute of Technology (GZLGXM-04), the National Natural Science Foundation of China (52104204), and the Natural Science Foundation of Shandong Province (ZR2021QE170), which are gratefully acknowledged.

\section{References}

[1] R. P. Mcneal, "Hydrodynamic entrapment of oil and gas in Bisti field, San Juan county, New Mexico," AAPG Bulletin, vol. $45,1961$.

[2] X. Li, Z. Cao, and Y. Xu, "Characteristics and trends of coal mine safety development," Energy Sources, Part A: Recovery, Utilization, and Environmental Effects, pp. 1-19, 2020.

[3] C. Ö. Karacan and K. Luxbacher, "Stochastic modeling of gob gas venthole production performances in active and completed longwall panels of coal mines," International Journal of Coal Geology, vol. 84, no. 2, pp. 125-140, 2010.

[4] P. Hou, X. Liang, F. Gao, J. Dong, J. He, and Y. Xue, "Quantitative visualization and characteristics of gas flow in 3D pore-fracture system of tight rock based on Lattice Boltzmann simulation," Journal of Natural Gas Science and Engineering, vol. 89, Article ID 103867, 2021.

[5] L. D. Connell, "Coupled flow and geomechanical processes during gas production from coal seams," International Journal of Coal Geology, vol. 79, no. 1, pp. 18-28, 2009.

[6] P. Hou, X. Liang, Y. Zhang, J. He, F. Gao, and J. Liu, "3D multi-scale reconstruction of fractured shale and influence of fracture morphology on shale gas flow," Natural Resources Research, vol. 30, no. 3, pp. 2463-2481, 2021.

[7] W. Shen, G. Shi, Y. Wang, J. Bai, R. Zhang, and X. Wang, "Tomography of the dynamic stress coefficient for stress wave prediction in sedimentary rock layer under the mining additional stress," International Journal of Mining Science and Technology, vol. 31, no. 4, pp. 653-663, 2021.

[8] M. Wang, "Rapid seam opening technology of mine shaft sinking in $1000 \mathrm{~m}$ deep mine with high outburst seam group," Coal Science and Technology, vol. 43, no. 5, pp. 71-73, 2015.

[9] Q. Zou, B. Lin, C. Zheng et al., "Novel integrated techniques of drilling-slotting-separation-sealing for enhanced coal bed methane recovery in underground coal mines," Journal of
Natural Gas Science and Engineering, vol. 26, pp. 960-973, 2015.

[10] X. Li, S. Chen, Q. Zhang, X. Gao, and F. Feng, "Research on theory, simulation and measurement of stress behavior under regenerated roof condition," Geomechanics and Engineering, vol. 26, no. 5, pp. 49-61, 2021.

[11] L. Yuan, H. Guo, and P. Li, "Theory and technology of goaf gas drainage with large diameter surface boreholes," Journal of China Coal Society, vol. 38, no. 1, pp. 1-8, 2013.

[12] M. Ahmadi, L. Ansaloni, M. Hillestad, and L. Deng, "Solvent regeneration by thermopervaporation in subsea natural gas dehydration: an experimental and simulation study," Industrial \& Engineering Chemistry Research, vol. 60, no. 17, pp. 6262-6276, 2021.

[13] S. Yin, Z. Li, D. Song et al., "Experimental study on the infrared precursor characteristics of gas-bearing coal failure under loading," International Journal of Mining Science and Technology, vol. 31, no. 5, pp. 901-912, 2021.

[14] L. Zhen, H. L. Zeng, and L. Y. Yong, "Effects of moisture on characteristics of coal-bed methane seepage," Disaster Advances, vol. 7, no. 5, pp. 101-112, 2014.

[15] X. Liang, P. Hou, and Y. Xue, "A fractal perspective on fracture initiation and propagation of reservoir rocks under water and nitrogen fracturing," Fractals, vol. 29, no. 7, Article ID 2150189, 2021.

[16] C. Ö. Karacan, F. A. Ruiz, M. Cotè, and S. Phipps, "Coal mine methane: a review of capture and utilization practices with benefits to mining safety and to greenhouse gas reduction," International Journal of Coal Geology, vol. 86, no. 2-3, pp. 121-156, 2011.

[17] R. Agaiev, V. Vlasenko, K. Dudlia, M. Kyrychenko, and D. Prytula, "On the possibility of coalbed methane extraction as a source of energy under the hydrodynamic impact on the outburst coal seam," Advanced Engineering Forum, vol. 25, pp. 106-112, 2017.

[18] X. Kong, S. Li, E. Wang et al., "Experimental and numerical investigations on dynamic mechanical responses and failure process of gas-bearing coal under impact load," Soil Dynamics and Earthquake Engineering, vol. 142, Article ID 106579, 2021.

[19] Q. Tu, Y. Cheng, S. Xue, T. Ren, and X. Cheng, "Energylimiting factor for coal and gas outburst occurrence in intact coal seam," International Journal of Mining Science and Technology, vol. 31, no. 4, pp. 729-742, 2021.

[20] X.-L. Li, S.-J. Chen, S.-M. Liu, and Z.-H. Li, “AE waveform characteristics of rock mass under uniaxial loading based on Hilbert-Huang transform," Journal of Central South University, vol. 28, no. 6, pp. 1843-1856, 2021.

[21] P. Phurkhao, "Transient response of an infinite row of collinear Griffith cracks in a saturated porous medium," Theoretical and Applied Fracture Mechanics, vol. 99, pp. 205-216, 2019.

[22] A. Soleymanzadeh, A. Helalizadeh, M. Jamialahmadi, and B. S. Soulgani, "Development of a new model for prediction of cementation factor in tight gas sandstones based on electrical rock typing," Journal of Natural Gas Science and Engineering, vol. 94, no. 10, Article ID 104128, 2021.

[23] T. Tamaogi, Y. Sogabe, and T. Tamaogi, "Examination of validity for viscoelastic split hopkinson pressure bar method," Time Dependent Constitutive Behavior and Fracture/Failure Processes, vol. 3, pp. 77-83, 2011.

[24] P. Sadavarte, S. Pandey, and J. D. Maasakkers, "A high-resolution gridded inventory of coal mine methane emissions for India and Australia," Atmospheric and Oceanic Physics, vol. 2107, Article ID 10317, 2021. 
[25] F. Yan, J. Xu, S. Peng et al., "Breakdown process and fragmentation characteristics of anthracite subjected to highvoltage electrical pulses treatment," Fuel, vol. 275, Article ID 117926, 2020.

[26] C. Jiang, Y. Yang, W. Wei, M. Duan, and T. Yu, “A new stressdamage-flow coupling model and the damage characterization of raw coal under loading and unloading conditions," International Journal of Rock Mechanics and Mining Sciences, vol. 138, no. 5, Article ID 104601, 2021.

[27] X. Li, S. Chen, E. Wang, and Z. Li, "Rockburst mechanism in coal rock with structural surface and the microseismic (MS) and electromagnetic radiation (EMR) response," Engineering Failure Analysis, vol. 124, no. 6, Article ID 105396, 2021.

[28] F. Yan, J. Xu, S. Peng et al., "Effect of capacitance on physicochemical evolution characteristics of bituminous coal treated by high-voltage electric pulses," Powder Technology, vol. 367 , pp. $47-55,2020$.

[29] Y. Meng and Z. Li, "Experimental comparisons of gas adsorption, sorption induced strain, diffusivity and permeability for low and high rank coals," Fuel, vol. 234, pp. 914-923, 2018.

[30] D. Mohr, G. Gary, and B. Lundberg, "Evaluation of stressstrain curve estimates in dynamic experiments," International Journal of Impact Engineering, vol. 37, no. 2, pp. 161-169, 2010.

[31] S. Turnell, "Reforming the banking system in Burma: a survey of the problems and possibilities," Arabian Journal of Geosciences, vol. 12, no. 13, p. 411, 2002.

[32] A. R. Bagherieh, N. Khalili, and G. Habibagahi, "Drying response and effective stress in a double porosity aggregated soil," Engineering Geology, vol. 105, no. 1-2, pp. 44-50, 2009.

[33] A. B. Zhuravlev, V. I. Karev, Y. F. Kovalenko, and K. B. Ustinov, "The effect of seepage on the stress-strain state of rock near a borehole," Journal of Applied Mathematics and Mechanics, vol. 78, no. 1, pp. 56-64, 2014.

[34] Z. Li, J. Peng, L. Li, L. Qi, and W. Li, "Novel dynamic multiscale model of apparent diffusion permeability of methane through low-permeability coal seams," Energy \& Fuels, vol. 35, no. 9, pp. 7844-7857, 2021.

[35] J. A. Pajares, J. J. Pis, A. B. Fuertes, A. J. Pérez, M. Mahamud, and J. B. Parra, "Influence of coal preoxidation and reactive gas flow rate on textural properties of active carbons," Characterization of Porous Solids II, Proceedings of the IUPAC Symposium (COPS 11), vol. 62, pp. 347-355, 1991.

[36] T. I. Urbancic and C. I. Trifu, "Recent advances in seismic monitoring technology at Canadian mines," Journal of Applied Geophysics, vol. 45, pp. 225-237, 2000.

[37] M. K. Billstr, C. Broman, and J. Schneider, "Zn-Pb ores of Mississippi valley type in the lycksele-storuman district, northern Sweden: a possible rift-related Cambrian mineralisation event," Minerals, vol. 2, no. 4, pp. 169-207, 2012.

[38] C. R. Claskson and B. M. Bustin, "Binary gas adsorption desorption isotherms: effect of moisture and coal composition upon carbon dioxide selectivity over methane," International Journal of Coal Geology, vol. 42, pp. 241-271, 2000.

[39] S. Wu, P. Ke, and J. Huang, "Research progress of sodium carboxymethyl cellulose," Chemical Engineering \& Equipment, vol. 261, no. 10, pp. 249-250, 2018.

[40] V. Januário, D. A. Ávila, M. A. Penetra et al., "Evaluation of treatment with carboxymethylcellulose on chronic venous ulcers," Anais Brasileiros de Dermatologia, vol. 91, no. 1, pp. 17-22, 2016.

[41] D. Pratap and S. Anantha Ramakrishna, "Nanoporous alumina microtubes for metamaterial and plasmonic applications," Pramana, vol. 95, no. 3, p. 136, 2021.
[42] J. Matusiak, E. Grzạdka, M. Paszkiewicz, and J. Patkowski, "Complexes of fluorinated, silicone and hydrocarbon surfactants with carboxymethylcellulose and their influence on properties of the alumina suspension," Colloid \& Polymer Science, vol. 297, no. 5, pp. 677-687, 2019.

[43] A. M. Alsabagh, M. I. Abdou, A. A. Khalil, H. E. Ahmed, and A. A. Aboulrous, "Investigation of some locally water-soluble natural polymers as circulation loss control agents during oil fields drilling," Egyptian Journal of Petroleum, vol. 23, no. 1, pp. 27-34, 2014.

[44] R. S. Weis and T. K. Gaylord, "Electromagnetic transmission and reflection characteristics of anisotropic multilayered structures," Journal of the Optical Society of America A, vol. 4, no. 9, pp. 1720-1740, 1987.

[45] S. Liu, X. Li, D. Wang, and D. Zhang, "Experimental study on temperature response of different ranks of coal to liquid nitrogen soaking," Natural Resources Research, vol. 30, no. 2, pp. 1467-1480, 2021. 